Estudios sobre armas antiguas, arte militar $\mathrm{y}$ vida cultural en oriente y occidente XXXVII (2017), pp. 153-170

ISSN: 0436-029X

doi: 10.3989/gladius.2017.06

\title{
LAS NUEVE REGLAS DE LA ESPADA DE DOS MANOS, Y LA PRÁCTICA DE LA ESGRIMA EN ZARAGOZA HACIA 1526
}

\author{
THE NINE RULES OF THE TWO-HANDED SWORD, AND \\ THE PRACTICE OF FENCING IN SARAGOSSA AROUND 1526
}

POR

Miguel GonzÁlez Ancín* y Otis Towns**

\section{RESUMEN - ABstract}

El artículo estudia uno de los dos documentos más antiguos en español de tratadística de esgrima. Para tratar de averiguar su autoría se recaba información sobre su entorno más inmediato de producción, con nuevos documentos sobre la enseñanza de la esgrima, exámenes, contratos de aprendices para los grados de esgrima y sus concesiones, licencias, nombramientos, etc. Esto resulta en la aparición de algunos maestros mayores y maestros de esgrima prácticamente desconocidos hasta la fecha, cuya mano pudo escribir el texto.

This article studies one of the two oldest treatises on fencing written in Spanish. With the purpose of finding out who authored this text, this article gathers information on where and how it was produced, with new documents on teaching fencing, exams, contracts from apprentices for fencing degrees, and their concessions, licences, appointments, etc. The new documents uncover some practically unknown high masters and fencing masters, whose hand could have written the treatise.

\section{Palabras Clave - Keywords}

Esgrima; maestro mayor; Pablo de Peralta; Zaragoza; enseñanza.

Fencing; high master; Pablo de Peralta; Saragossa; teaching.

\section{Cómo CITAR este ARTículo / Citation}

González Ancín, M. y Towns, O. (2017): «Las nueve reglas de la espada de dos manos, y la práctica de la esgrima en Zaragoza hacia 1526». Gladius, XXXVII: 153-170. doi: 10.3989/gladius.2017.06

\section{PRELIMINARES}

Cuando realizábamos unas comprobaciones en el Archivo Histórico de Protocolos de Zaragoza, nos topamos con un documento en castellano sobre el manejo de la espada de dos

\footnotetext{
*Zaragoza, miguelg.ancin@gmail.com / ORCID iD: http://orcid.org/0000-0002-3459-181X.

** Los Angeles, otis.towns@gmail.com / ORCID iD: http://orcid.org/0000-0001-8170-1287.
} 
manos. ${ }^{1}$ Conscientes de lo escasos que son estos textos sobre tratadística de esgrima ${ }^{2}$ en lengua española anteriores a 1582, hasta el punto de que había muchas posibilidades de que fuese el segundo o primero más antiguo conocido, decidimos profundizar en el asunto, sobre todo en tratar de conocer el entorno de producción y de enseñanza de la esgrima en Zaragoza, con el objetivo de tratar de averiguar quién había ordenado redactarlo, o para qué. Esto también resultó al final en un estudio de algunos otros aspectos desconocidos de la historia de la esgrima en torno a esas décadas y zonas.

\section{LA ESGRIMA TRADICIONAL Y LAS REGLAS}

El conjunto del arte de las armas antes de finales del siglo XVI en la península incluía un amplio rango de armas, tales como diversas clases de espadas, broqueles, lanza, daga, etc. Esta práctica se denominaba antiguamente como esgrima, hasta que con las aportaciones y nueva visión de nuevos esgrimistas — principalmente Pacheco- comenzó a denominarse con otros nombres, tales como "Destreza Común" o "Destreza Vulgar". La Verdadera Destreza nació en $1582,{ }^{3}$ como nuevo sistema del que conocemos bien el funcionamiento, debido a los tratados que se han conservado. Pero la esgrima tradicional ha tenido la mala suerte de perder la mayor parte de los autores, quedando la mayoría de sus enseñanzas solo reflejadas por los comentarios muy posteriores en gran medida provenientes de los esgrimistas de la nueva o Verdadera Destreza, Jerónimo Sánchez de Carranza y Luis Pacheco de Narváez. ${ }^{4}$

Por lo que sabemos, los primeros autores españoles de tratados de este sistema anterior de esgrima fueron Jaime Pons y Pedro de la Torre, que publicaron ambos en 1474, y de cuyos tratados perdidos tenemos noticia principalmente por Pacheco, conociéndose muy poco del primero $^{5}$ y aún menos del segundo. El siguiente autor de la esgrima tradicional, con un tratado en castellano, fue el que publicó en 1532, el famoso Francisco Román, ${ }^{6}$ maestro mayor y examinador para los reinos de Castilla, ${ }^{7}$ así como maestro de los pajes del rey, del que hablaremos más adelante. La obra del maestro Sayas y Alfaro también se perdió.

Además de estos textos que existieron, se conservan algunos como hay también lo que parece ser una traducción parcial de un tratado de Pietro Monte del latín original al castellano, conservado en El Escorial, y un texto de esgrima de origen indeterminado descubierto y publicado en 2009 por Manuel Valle ${ }^{8}$ y Dill Curtis, que parece poder situarse en los comienzos o mediados del siglo XVI, y que junto con el de este artículo constituyen los dos textos más antiguos sobre tratadística de la esgrima en castellano.

El aspecto principal del texto es que conforma en nueve reglas una serie de tretas, un rasgo central de la esgrima tradicional, en este caso para la espada de dos manos. En este sistema, las reglas constituían un método primitivo de enseñanza de artes marciales, sin un gran corpus teórico, ${ }^{9}$ para recordar movimientos preestablecidos enfocados a contextos o entornos especí-

1 Documento 1, AHPZ (Archivo Histórico de Protocolos de Zaragoza), sig. 2790, fol. 95, (Luis Barbarán, vol. 15271532). Figura 1. En adelante lo llamaremos Las nueve reglas de la espada de dos manos.

2 Nuestros agradecimientos a Juan Molina Fernández, que fue el primero que nos orientó en todo el asunto de la esgrima. También a Manuel Valle Ortiz, a Alberto Bomprezzi, a Alfonso Arráez Tolosa y especialmente a David Nievas Muñoz, por sus consejos en los comienzos de la investigación. Asimismo a Francisco Javier González Echeverría.

3 Nievas Muñoz, 2012: 33.

4 Valle Ortiz, 2012: 35.

5 Llompart Moragues, 1976-1977: 154.

6 Valle Ortiz y Dill Curtis, 2009: 248.

7 Guilmaín Alonso, 2014: 2453.

8 Valle Ortiz, 2012: 39-40.

9 Guilmaín Alonso, 2014: 2460. 
ficos. Sin embargo, parece que en general no eran técnicas, sino que su uso adecuado se cernía principalmente a los entrenamientos, a modo de ejercicios, y con una ejecución que dependía del que las usaba. Así que aun a pesar de ser aparentemente reglas sencillas que en muchos casos reflejaban movimientos intuitivos y naturales, fueron ganando en complejidad y su uso dependía totalmente de la experiencia y habilidad práctica del ejecutante..$^{10}$ Esta clase de aproximación se debió en parte a que los propios maestros de esgrima eran más hombres de acción, considerando que su técnica se asentaba en principios comprobados, y no prestaban una gran atención a la difusión de sus métodos. ${ }^{11}$

Dejaremos en manos de futuros investigadores y practicantes de esgrima los análisis pormenorizados de los términos lingüísticos y los aspectos técnicos que aparecen en las reglas, sobre lo cual nosotros solo podemos alumbrar algunos aspectos muy básicos, tales como que los términos que utiliza recuerdan a la escuela italiana. Por ejemplo, en la referencia al movimiento ascendente muntante, o como los de mandritto. Esto parece reafirmar la idea que ya se tenía de que existía una escuela común europea, muy similar a la italiana. Aparecen así mismo términos como fas montante, al que Carranza denomina como una treta, pero que no describe. $\mathrm{Y}$ en su conjunto, parecen no provenir de ninguna escuela de esgrima conocida ni obra publicada, sino ser el método de aprendizaje dispensado por algún determinado maestro a sus aprendices, dentro de la gran diferencia en contenido y estructura que existía entre los maestros de la esgrima tradicional. ${ }^{12}$

\section{LA PRODUCCIÓN DE LAS REGLAS}

Las nueve reglas de la espada de dos manos se encuentra como la última página de un tomo que contiene protocolos que los años de 1527 a 1532 de Luis Barbarán II, que en aquellos años era notario "real" o general, pero no de "caja" o de "número de cuarenta", notarios públicos con escribanía localizada. A estos notarios los designaba el rey. Un grupo importante de estos era deslocalizado pudiendo desplazarse por todo el reino, otros actuaban específicamente para instituciones, ${ }^{13} \mathrm{y}$ en nuestro caso parece que Luis Barbaran actuaba como escribano en varias escribanías de notarios de caja de Zaragoza. A la vez que redactaba documentos para notarios de caja, que eran protocolizados, Barbarán también poseía legajos él mismo, para sus propias actividades notariales como notario general, constituyendo entre otros el tomo que nos ocupa, y habiendo escrito de su mano el texto de esgrima. ${ }^{14}$

El texto está escrito sobre un folio doblado en octavo que ha perdido su otra mitad, por tanto no hay nada físico que lo conecte a otro documento, habiendo sido cosido a posteriori con el resto de documentos. Sin embargo, la página anterior contigua posee elementos también curiosos, como lo que parece ser una pequeña poesía, ${ }^{15}$ que parece apuntar a que Luis Barbarán

10 Bomprezzi, A. Las Escuelas de Esgrima Españolas. La "Verdadera Destreza” y la "Esgrima Común” http://www. esgrimaantigua.com/EsgrimaComun.php

11 Nievas Muñoz, 2012: 42.

12 Nievas Muñoz, 2012: 41-42.

13 Gracia Lasheras, 2014: 68-69.

14 Puede resultar un problema saber quien exáctamente escribe los documentos dentro de una escribanía. Aun presuponiendo que Luis Barbarán no tuviese ayudantes que redactasen sus documentos, hemos decidido asegurarnos. Al encontrar textos con la misma grafía y atestiguados por "Luis Barbarán, notario" en los volúmenes que producía otras escribanía podemos confirmar que es la propia mano del notario general Barbarán, y no la de uno de sus escribanos la que redactó el texto de esgrima. Ej: (AHPZ, sig. 3976, fol. 362r, Luis Sora 1527).

15 AHPZ Luis de Barbarán, sig. 2790, fol. 94v: "Dia de Sancta Polonia que es a nuebe/ de febrero no partí noche ata vinte/ del dicho mes, y a veinte vino el/ galgo y se perdió la llebre y a/ veinte y vno se tornó a yl". 
reutilizó papeles más antiguos, de otros ejercicios de su actividad, aprendizaje, incluso puede que alguno de motivaciones recreativas.

Las reglas están centradas en el folio, y son enlistadas ocupando completamente el anverso y gran parte del reverso. Al acabar el texto de esgrima se retoman otra vez anotaciones esta vez de tenor notarial, con una grafía mucho más acelerada y descuidada correspondiente a un bastardelo. ${ }^{16}$ Este bastardelo es el elemento que nos permite acotar el documento, puesto que hemos encontrado en el interior del tomo el mismo documento protocolizado, ya en limpio, donde aparece que éste se redactó el 16 de Diciembre de $1528 .{ }^{17}$ Por tanto, resulta claro que Luis Barbarán utilizó un folio usado, con un texto de esgrima que él mismo había producido antes con propósitos desconocidos, para tomar anotaciones rápidas y esquemáticas de los protocolos que iba redactando, y que luego pondría en limpio. Por tanto, es un documento anterior al 16 de Diciembre de 1528, y muy posiblemente no redactado en un pasado inmediato a esta fecha, sino en el que pudieron transcurrir muchos meses o incluso años, los suficientes para que ya no tuviese importancia para el notario.

Aunque nos daría un indicio fuerte, hasta la fecha no hemos encontrado ningún documento relacionado con esgrimistas que aparezcan en la escribanía de Barbarán o en documentos que él haya escrito o atestiguado para otras escribanías. Sin embargo, sí que hemos encontrado a jugadores, prebostes, maestros y un maestro mayor del arte de la esgrima en Zaragoza, que conformaban el proceso de enseñanza de la esgrima durante esos años concretos.

\section{LOS MAESTROS MAYORES DE LA CORONA DE ARAGÓN PENINSULAR}

Varios investigadores encontraron importantes documentos relacionados con la práctica y transmisión de la esgrima en Aragón, y más concretamente en Zaragoza, pero hasta donde nosotros sabemos, no se transmitieron al mundo del estudio de la esgrima, seguramente porque fueron publicados de manera tangencial en obras de otra temática, y hace mucho tiempo. El sistema de enseñanza y ejercicio de la esgrima en España giraba en torno a la figura de los maestros mayores en respectivas áreas. Este cargo, aparte de otorgar el monopolio a unos pocos, era una prestigiosa concesión real. ${ }^{18}$

Un buen número de los maestros mayores de la Corona de Castilla ${ }^{19}$ durante el siglo XV y XVI eran conocidos desde hace años, ${ }^{20}$ siendo el primero detectado el nombrado en 1478 , el

16 Esta grafía acelerada también parece pertenecer a la mano de Barbarán.

17 AHPZ, Luis Barbarán, sig. , 1528, fol. 49v. «Die septima mensis decembris anno MDXXVIII”, y fol.50: “Die xvi decembris de anno quo supra, eadem die que nos, Biçente de Bera, y Aldonza Copones, cónjuges, y (en blanco) de Bera, fija de los dichos cónjuges, de su grado y cierta sciencia ratificando, confirmando y emologando todos y qualesquiere actos fechos y enantados por los discretos Francisco Sebastián y Juan Penya notarios, agora de nuebo fazemos procuradores nuestros a los dichos Juan de Penya, Francisco Sebastián, Matheu Lop, Agostín Soriano, Salvador de Sanctaffé y Jerónimo Sánchez, notarios causídicos, habitantes en la ciudat de Çaragoça absentes, etc, a pleytos largamente, con poder de jurar y substituyr (tachado: prometemos) con esto enpero que no puedan los dichos procuradores míos renunciar ningún apellido criminal, dado ni dadero, por nos ni por el otro [...] prometemos tener por firme todo lo que por los dicho dichos nuestros procuradores sera dicho, fecho y procurado, dius obligacione, etc. Testigos los venerables mossén Miguel Rubiellos, clérigo, y Juan de Ansián, escudero, habitantes en la dicha ciudat de Çaragoça» (Véase final del Documento 1).

18 Nievas Muñoz, 2012: 82.

19 "Examinador mayor de todos nuestros reinos", reza el título al maestre Dorado y también así se le denomina a Román, pero también lo son así en sus reinos los de la Corona de Aragón peninsular. No parece posible que existan simultáneamente maestros mayores para todos los reinos con plenos poderes, y maestros mayores en coronas específicas, ya que sus competencias chocarían. Para ambos grupos se especifica en sus nombramientos un control total sobre la práctica de la esgrima, solo superada por los mandamientos reales. Parece más que cuando nombran tanto a Gómez Dorado o Francisco Román, se está nombrando a maestros mayores para todos los reinos de la Corona de Castilla.

20 Ceballos-Escalera, 1997: 77-108. También descritos en la obra de Leguina y Vidal (1904). 
maestre mayor Gómez Dorado, ${ }^{21}$ seguido de su sucesor hacia 1526, el maestre mayor Francisco Román, y luego el maestre mayor Benito Pérez. ${ }^{22}$ Sin embargo, no parece que fuese conocido en el mundo de la esgrima los de la Corona de Aragón, o más concretamente los de la parte continental de esta, puesto que no podemos asegurar que no haya algún otro cargo para las regiones más orientales de esta Corona, como Sicilia, Oristán, Nápoles, Neopatria, Baleares, áreas que no se mencionan en las competencias de estos maestros mayores de la Corona de Aragón, y parece muy lógico que así fuese, y existiesen en realidad tres maestros mayores del arte de la esgrima en los territorios hispánicos. ${ }^{23}$

\subsection{El maestre mayor Alfonso de Robles (1458-1508)}

En 1916 Serrano y Sanz publicó dentro del Boletín de la Real Academia española, en su sección de lexicología, ${ }^{24}$ nada menos que el título de maestro mayor de los reinos de Aragón, Valencia, y principado de Cataluña otorgado por Juan II al maestre Alfonso de Robles, pasando aparentemente desapercibido para los estudiosos de este campo. Es importante recalcar que el maestre Alfonso de Robles no fue el primero en su cargo, como se verá luego al hablar de su sucesor. El maestre Alfonso de Robles era barbero/cirujano, y su concesión, al igual que aparentemente en todas las ocasiones que este título era otorgado, provenía del deseo de personas cercanas al rey, o de la propia iniciativa regia. En su caso particular, no se especifica de quién parte la iniciativa, con un genérico "domésticos y parientes nuestros". ${ }^{25}$ Seguidamente el documento describe los privilegios del maestre mayor para los reinos de Aragón, Valencia y principado de Cataluña, cinco de los cuales coinciden exactamente con los de los maestros mayores de la Corona de Castilla. ${ }^{26}$

1- Que no puedan levantar bachiller, prebostes o maestros excepto él.

2- Que no se puedan poner plaza en juego sino por él.

3- Que si llama a los prebostes, maestros, y no vienen, puede multarlos.

4- Capacidad de reexaminar a cualquier maestro previo, e inhabilitarlo.

5- Penalizar a los que enseñen a judíos, moros o esclavos. ${ }^{27}$

El cuarto punto aparece quizá de un modo un poco diferente con ese "parar plaza o plazas", pero parece que puede referirse a lo mismo, a la capacidad de parar zonas de entrenamiento, clases o escuelas de armas. ${ }^{28}$ En Zaragoza en concreto, había al menos un sitio fijo para los exámenes y demostraciones, que parece corresponder con lo que sería una sala o escuela de armas, una palestra, o ambas cosas, localizada en un corral del barrio de San Felipe.

21 Leva Cuevas, 2004: 121.

22 Guilmaín Alonso, 2014: 2455.

23 Mallorca poseía una considerable densidad de esgrimistas (Llompart Moragues, 1976-1977: 150-154), por tanto, resultaría lógico regular sus prácticas con una figura similar.

24 Serrano y Sanz, 1916: 240. También lo hemos incluido en el apéndice, por estar directamente conectado con el siguiente maestro mayor, como Documento 2.

25 El maestro mayor era un puesto otorgado en esta época y anteriormente a los cercanos del rey, o a personajes que contaba con el amparo o bendición de los continuos de él, aparentemente por servicios de empresas militares, o protección, ya sea Gómez Dorado y Román (Guilmaín Alonso, 2014: 2453), Robles, o Peralta.

26 Nievas Muñoz, 2012: 77.

27 Sin embargo, en la transcripción de Serrano y Sanz no se especifica una multa para la transgresión de los puntos 1 y 2 .

28 Nievas Muñoz, 2012: 78. 


\subsection{El maestre mayor Pablo de Peralta (1508-1540)}

El maestro Alfonso de Robles falleció aparentemente en 1508, fecha en la que el rey Fernando el Católico otorgó el título vitalicio de maestro mayor de los reinos de Aragón, Valencia y Cataluña, y también los recuperados condados del Rosellón y Cerdaña, al maestre Pablo de Peralta. ${ }^{29}$

Esta vez fue por intercesión del hijo bastardo del rey Fernando, el arzobispo de Zaragoza y Monreal, don Alonso de Aragón, lugarteniente de Aragón, del cual debemos recordar su conocida participación en múltiples conflictos bélicos, como en 1507 en Nápoles, ${ }^{30}$ que puede apuntar a que supiese del maestro Pablo de Peralta a través de algún contexto armado.

Y hasta donde sabemos, parece que tampoco era conocido este maestro mayor en el mundo de la esgrima, a pesar de que se publicó un documento en el que aparecía en 1917, pero esta vez de manera tangencial al hablar del escultor Jolí. ${ }^{31}$ En el documento de su nombramiento por Fernando el Católico, se refiere que se le va a entregar este puesto vitalicio por muerte del maestre Alfonso de Robles, su antecesor en el cargo, y que se le da con los mismos privilegios, prerrogativas, exenciones, franquezas, etc, pero no se describen. ${ }^{32}$ Afortunadamente, como ya hemos visto, las conocemos a través del nombramiento al maestre Alfonso de Robles, las mismas que los maestros mayores de la Corona de Castilla. Además, también se refiere que existieron otros maestros mayores de la Corona de Aragón continental antes del maestro mayor Alfonso de Robles. ${ }^{33}$

El salario y ganancias se citan, pero no se describen ni en el documento del maestre Alfonso ni en el de Pablo, por tanto tenemos que confiar en que sea similar al descrito para los maestros mayores de la Corona de Castilla. ${ }^{34}$

Después de jurar obediencia a la princesa Juana, Fernando blinda al maestro mayor describiendo como todos los beneficios del maestre Pablo de Peralta han de ser respetados por prácticamente todos los cargos administrativos, y de Justicia, y se les advierte de que de no ser así incurrirán en la indignación e ira regia, y se tomará de sus bienes, como multa, la importante suma de 3000 florines.

Existe, sin embargo, otra capacidad de la que parece disfrutar el maestro mayor. Parece tener la facultad de dar licencia a otros duchos en el arte, ya no solo para demostrar o enseñar, sino para poder tener capacidades similare ${ }^{35}$ a las propias del maestro mayor, ${ }^{36}$ inhabilitando y expulsando de zonas y ciudades a aquellos maestros que no estén en el sistema. ${ }^{37}$ Esto parece coincidir con los privilegios que se citan en los nombramientos reales para el cargo, pudiendo

29 Documento 3, Archivo de la Corona de Aragón, Registro de la Cancillería Real num. 3542 (Oficialium 5), ff.185r$186 r$.

30 También en la conocida conquista de Tudela en 1512.

31 Abizanda y Broto, 1917: 107-108.

32 Documento 3.

33 Ibid. "..Alonso de Robles y otros predecessores vuestros en el dicho officio..".

34 Se conocen algunos ejemplos de salarios de los maestros mayores de Castilla de finales del s. XVI, y parece que rondaba los 100 ducados por año. (Nievas Muñoz, 2012) Nievas también refiere que este salario podía ser insuficiente para el maestre mayor.

35 Un caso sería el del maestre mayor Gómez Dorado delegando en el maestre Alfonso de Gandía, o del maestre mayor Francisco Román al maestre Diego Bernal de Heredia (Guilmaín Alonso, 2014: 2454).

36 Por ejemplo conferir a determinados maestros la capacidad para requerir la carta de examen a otros esgrimidores, e imponer penas (Leva Cuevas, 2004: 119).

37 Documento 4, AHPZ, sig. 3884, fol. 53r. (Antón de Salabert, 7 de abril de 1516). El maestre mayor otorga una licencia a otro maestro para que pueda ejercer y demostrar esgrima en todos los territorios de su ámbito, excepto en las tres capitales de los tres territorios, requiriendo al parecer los beneficios en joyas. Sin embargo, no especifica que le pertenezca una parte de las ganancias que obtendrá este maestro, como sí ocurre otras veces. 
tener maestros para "parar plazas" (documento 2), personas de confianza, criados, etc. Estos nombramientos de lugartenientes para zonas o reinos específicos, maestros, etc., y los respectivos poderes concedidos a sus subordinados, bien como lugartenientes del maestro mayor para reinos o zonas específicas, o bien como criados para la supervisión de los maestros, generaba una estructura jerarquizada y muy centralizada de la enseñanza en todas las zonas que formaban parte de su extenso ámbito, además de beneficios económicos para su persona, ${ }^{38}$ otorgados por las licencias concedidas, o confirmadas, directa o indirectamente por él. ${ }^{39}$

El maestre Pablo de Peralta nos interesa especialmente puesto que coincide en el tiempo con la fecha aproximada de producción de las Nueve reglas de la espada de dos manos. Le hemos visto en el ejercicio de sus funciones como evaluador, supervisor y también ejerciendo labores de enseñanza en Zaragoza, a lo largo de las primeras décadas del siglo XVI. Su nombramiento fue después confirmado por el rey Carlos en $1518,{ }^{40}$ y aunque desconocemos cuando falleció, nos consta que estuvo vivo al menos hasta $1533 .{ }^{41}$ Lo más lógico y coherente por los datos que da Cabezudo Astrain sería suponer que falleció en 1540, fecha en la que dice que se ha nombrado al primer maestro mayor de la Corona de Aragón del que él tiene conocimiento, el maestro Luis de Torrebanias. ${ }^{42}$

\subsection{El maestro mayor Luis de Torrebanias (1540- ?)}

Nos consta que existió el maestro mayor de esgrima de la Corona de Aragón peninsular al que se refiere Cabezudo Astrain, y de hecho siguió en el ejercicio de sus funciones al menos hasta $1545 .{ }^{43}$ El 29 de septiembre de este año, en Huesca, el maestro de esgrima Juan de Bastero declara ser lugarteniente para el Reino de Aragón y Principado de Cataluña del maestre Luis Torribania ${ }^{44}$ maestro mayor de Aragón, Valencia, Cataluña, y condados del Rosellón y Cerdaña. El lugarteniente da permiso a Alexandre Camañas para que pueda enseñar esgrima en todo el Reino de Aragón por tiempo de cuatro meses. La cuarta parte de lo que perciba como salario de maestro de esgrima por los alumnos que tuviese debe ser entregada al lugarteniente, que la entregará al maestro mayor de la Corona de Aragón peninsular.

\section{LA ENSEÑANZA DE LA ESGRIMA EN ZARAGOZA HACIA 1526}

La competencia en el arte de la esgrima estaba graduada en 3 grados: el de bachiller o jugador, el de preboste y el de maestro.

El grado de bachiller era el primero de todos, pero no hemos localizado ninguna referencia a ellos como "bachiller" sino como lo que parece ser un equivalente llamado grado de

\footnotetext{
38 Esta clase de beneficios podrían ser con las que el maestre mayor solventase parte de un salario que resultaba pequeño (véase nota 36). También entraría dentro de esta clase de ganancias las que cobraban por los exámenes.

39 Véase el documento que expedirá el lugarteniente del maestre mayor de la Corona de Aragón peninsular Torrebanias en 1545 , descrito en el siguiente apartado.

40 AHPZ, sig 3521, fol. 39v, (Juan de Gurrea, 8 de marzo de 1526).

41 AHPZ, sig 3525, ff. 577r-578r, (Juan de Gurrea, 25 de noviembre de de 1533), dispondŕa de unas casa alquiladas en el barrio de San Miguel a partir de 1533.

42 Cabezudo Astrain, 1962: 83.

43 Archivo Provincial de Huesca, sig. 725, ff. 204v-205r, (Juan de Canales, 29 de septiembre de 1545).

44 Sic. Desconocemos si el nombre real es el que da Cabezudo Astrain, "Torrebanias", o Torrebania.
} 
"jugador", ${ }^{45}$ nivel para el que quizá no era usual establecer un contrato de enseñanza/concesión de título con un maestro de esgrima.

El siguiente grado de competencia era el de preboste. En 1917 se publicó dentro de un libro sobre historia del arte una sección sobre Gabriel Jolí, escultor francés afincado en Zaragoza, de gran renombre en las primeras décadas del siglo XVI. El estudio contenía una transcripción de la concesión del título de preboste de esgrima para Jolí, otorgada por el maestro Luis de Amada, como sustituto del maestro mayor Pablo de Peralta, que había recibido el título por el rey Fernando el Católico. Asimismo estaban presentes los maestros Sebastián de Soria, habitante en Zaragoza, y Morim Gallici. Sin embargo, tampoco hemos encontrado publicaciones de esgrima que lo refieran.

Seguiremos la trayectoria de dos estudiantes de esgrima en 1526 y 1527: Francisco Cristóbal y Francisco de Cambra, en su adquisición del título de preboste y maestro. En el caso de Francisco Cristóbal, que no parece que ostente ningún título previo, ${ }^{46}$ se le conceden los grados de jugador y de preboste de una sola vez, demostrando su suficiencia frente a los maestros. Además, no parece que se hubiesen pactado plazos de enseñanza ni concesión, como sí que hemos visto que se podían hacer para obtener el título de maestro de esgrima. También conviene destacar que se obtenía el título específicamente en unas armas concretas, así difieren las de la maestría de $1505^{47}$ y las de las prebostías y maestrías de $1515^{48}$ y $1526-1527$ (espada de dos manos y espada y broquel pequeños).

El examen de preboste se realizó dentro del corral ${ }^{49}$ de unas casas en el barrio de San Felipe de Zaragoza. Rodeados por un amplio público, Gabriel Jolí, preboste de esgrima, apadrina a Francisco Cristóbal, al cual parece que él mismo había enseñado esgrima, para que sea examinado por el maestro mayor Pablo de Peralta, estando presentes tres maestros más: Luis de Folguera, Sebastián de Soria y Pedro Román, todos habitantes de Zaragoza. Pablo de Peralta le pide a Sebastián de Soria que lo examine, y ambos luchan con espadas de dos manos y espada y broquel pequeño. Después proceden a preguntarle sobre asuntos pertinentes al arte, quedando los cuatro maestros muy contentos. En este momento el padrino le hace jurar que con todo su poder con la espada desenvainada defenderá la Santa Fé católica, a las viudas, pupilos y huérfanos, y se instituye como preboste y jugador de esgrima en espada de dos manos y espada y broquel pequeños. ${ }^{50}$

Sin embargo, parece que la concesión real del título de preboste podía ser un acto posterior con más ceremonial y, en general, con más maestros presentes. ${ }^{51}$ Lo comentamos porque el examen previo fue para dos esgrimistas a la vez, Francisco Cristóbal y Francisco de Cambra, y da a entender que los dos han superado el examen. Sin embargo, posteriormente encontramos la concesión del grado de preboste para Francisco de Cambra el 8 de Marzo del mismo año, ${ }^{52}$ en la que además del maestro mayor están presentes otra vez los maestros Luis de Folguera y Sebastián de Soria, pero además el también maestro de esgrima Pedro Marco Oliver, y los

45 En este punto no estamos totalmente seguros. Por el documento de examen que encontramos diríamos que jugador y bachiller son el mismo título, pero el documento de examen referido por Cabezudo Astrain dice que preboste es equivalente a bachiller, algo que de ser así no coincide con los grados descritos en la bibliografía consultada, ya que siempre aparece bachiller como grado inferior a preboste.

46 Documento 5, AHPZ, sig. 3521, ff. 4r-8r, (Juan de Gurrea, 2 de enero de 1526).

47 En espada, broquel y lanza (Cabezudo Astrain, 1962: 86).

48 Gabriel Joli domina un gran número de armas (Abizanda y Broto, 1917: 108).

49 Otras ubicaciones para exámenes eran por ejemplo las plazas públicas (Leva Cuevas, 2004: 121).

50 Documento 5.

51 El examen se realizaba tanto para los rangos de bachiller como de preboste y maestro, acto solemne hecho en público y ante uno o varios maestros congregados (Nievas Muñoz, 2012: 78; Anglo 2000: 9).

52 AHPZ, sig 3521, ff. 39v-40r, (Juan de Gurrea, 8 de marzo de 1526). 
maestros Pedro Flores y Juan de San Gil, maestros en espada y broquel pequeños. Este acto parece coincidir con el documento que ya teníamos de concesión de grado de preboste a Gabriel Jolí, ${ }^{53}$ por su ceremonial y extensión similar.

Posteriormente a la prebostía, el esgrimista podía tratar de obtener el título de maestro de esgrima, bien con un maestro que contase con una carta de examen de uno de los dos maestros mayores,${ }^{54} \mathrm{o}$ bien con el propio maestro mayor. Hemos encontrado una obligación que se establece entre el preboste de esgrima Francisco Cristóbal y el maestro mayor Pablo de Peralta para que le enseñe esgrima ${ }^{55}$ y se comprometa a darle el título de maestro en una fecha señalada. A cambio, el alumno se compromete a pagarle una cantidad de 10 florines, que en parte justifica el maestro mayor por los gastos que acontecerán de la comida que se realizará con los maestros que lo examinen. Esta tradición resulta congruente con la adquisición de títulos en los Estudios Generales de la época, particularmente las maestrías y doctorados. Asimismo, la cantidad de 10 florines de oro, no parece pequeña, y quizá limitaba la obtención de tal título, ${ }^{56}$ como de igual manera se hacía para otorgar el grado distintivo de doctor con respecto al licenciado, entre los universitarios. La fecha elegida parece ser la Pascua de mayo de 1526. Sin embargo hemos encontrado un documento que notifica que se le ha entregado el título de maestro a Francisco Cristóbal, pero al año siguiente. ${ }^{57}$ Desconocemos las razones para el retraso, pudiendo ser que Francisco no pagó, o necesitó más tiempo, u otras causas.

Parece lógico pensar que el documento de las nueve reglas sería producido en alguno de estos contextos o similares en los que se practicase la lucha con espada de dos manos, en un entorno cuya enseñanza por parte de los maestros de esgrima en Zaragoza estaba controlada por el maestro mayor de los reinos de Aragón, Pablo de Peralta.

\section{LOS MAESTROS DE ESGRIMA DE ZARAGOZA}

Uno de los aspectos más curiosos de la esgrima tradicional es que sus maestros poseían muy frecuentemente otro oficio, y los estamentos sociales y profesiones donde se vertía el arte era muy variopinto. ${ }^{58}$ Se debía enseñar a cualquiera que lo pidiese. En muchos documentos no se hace alusión a la condición de preboste, ni de maestro de esgrima del ejecutante de la pieza notarial, sino que aparece su profesión.

Un ejemplo claro de esta circunstancia sería el del maestro Luis de Folguera alias de Amada, que habíamos detectado como tejedor, pero no podíamos tener la seguridad de que fuese nuestro maestro de esgrima. El maestre Luis ya aparecía entregando el título de preboste a Gabriel Jolí, como sustituto del maestre mayor Peralta. Estaba casado con Catalina de Arébalo, e hizo testamento en $1525 .{ }^{59}$ Con respecto al maestre Sebastián de Soria, sin tener total seguridad de que se trate de la misma persona, el único homónimo que hemos encontrado parece que era un corredor de ropa.

53 Abizanda y Broto, 1917: 107-108

54 Tenemos el caso de dos maestros de esgrima y un bachiller concediendo una carta de examen (Cabezudo Astrain, 1962: 85).

55 Documento 6, AHPZ, sig 3521, ff. 29r-30v, (Juan de Gurrea, 19 de febrero de 1526). Este documento confirma lo que algunos investigadores sospechaban: "es lógico pensar que la transmisión del conocimiento en el manejo de las armas era directa entre el maestro y el alumno" (Guilmain Alonso, 2014: 2460).

56 Leva Cuevas, 2004: 121, nota 28.

57 AHPZ, sig. 3521, ff. 115v-116r, (Juan de Gurrea, 30 de septiembre de 1527), también concedido a Pedro Calahorra, pelaire.

58 Guilmaín Alonso, 2014: 2459

59 AHPZ, sig. 429 , ff.1v-4r, (Francisco la Tobería, 8 de julio de 1525). 
El caso de Gabriel Jolí es llamativo, ya que a pesar de no ser maestro de esgrima, es preboste en un gran número de armas. De origen francés, participó en la creación de multitud de esculturas religiosas.

Con respecto a Pedro Marco Oliver, ${ }^{60}$ hemos encontrado un documento relacionado con el alquiler de unos locales en El Coso para enseñar esgrima, pero de otros esgrimidores zaragozanos como Pedro Flores y Juan de San Gil, no hemos encontrado más datos.

Por último tenemos a los dos a nuestro juicio más interesantes, por un lado el maestro mayor Pablo de Peralta, y el maestro Pedro Román, juntos en 1526 en Zaragoza. Este hecho es llamativo porque hacia 1526 el maestro Francisco Román, de Sevilla, será nombrado maestro mayor de los reinos de Castilla, un hombre del que se conoce que su mujer se llamaba Catalina Martínez de la Guarda, y un hermano llamado Diego Román, naturales de Carmona ${ }^{61}$ Existen algunos Román en Zaragoza, pero las genealogías son tan densas que no sabemos si el famoso maestro Francisco Román de Sevilla está conectado a estas. No hemos encontrado ningún contacto con Sevilla ni su área, excepto en el nombramiento de Peralta en 1508. En cualquier caso, resulta razonable pensar que el maestro mayor Pablo de Peralta y el colega coetáneo de Castilla, y maestro de los pajes, se conociesen.

\section{CONCLUSIONES}

Los datos apuntan a que en esta época existieron al menos dos cargos de maestros mayores de arte de la esgrima simultáneos: uno para la Corona de Castilla, controlando un ámbito de gran extensión y quizá más unido a la corte, y otro para la Corona de Aragón peninsular, donde al parecer el cargo existió desde antes de 1458.

Las nueve reglas de la espada de dos manos es uno de los dos textos más antiguos conocidos hasta la fecha sobre tratadística de la esgrima en lengua castellana, y no parece corresponder con ninguna escuela conocida, teniendo una clara influencia italiana. Con respecto al texto hallado en 2009, sin fecha, su tenor es mucho más escueto y directo, lo cual recuerda mucho más a unos esquemas de entrenamiento que a que sea un fragmento de una obra desconocida, algo que parece más probable con el texto publicado por Manuel Valle y Mary Dill Curtis.

Se produjo por el notario real zaragozano Luis Barbarán, en algún momento desde el comienzo de su ejercicio como escribiente, con toda seguridad en fechas anteriores al final de 1528 , haciendo muy probable que a día de hoy se trate del texto más antiguo de tratadística de esgrima en lengua castellana, seguramente redactado en algún asunto relacionado con la docencia de la esgrima tradicional en la ciudad de Zaragoza, zona con una intensa actividad esgrimista controlada desde 1508 por el maestro mayor de la Corona de Aragón peninsular, Pablo de Peralta. Apuntan en esta dirección las dos prebostías otorgadas en 1526 (las de Cambra y Cristóbal) y también la maestría (Cristóbal) y prebostía (Pedro de Calahorra) conferidas en 1527, que contienen como una de las dos destrezas adquiridas, la de la espada de dos manos. Pero hasta que no tengamos un documento que demuestre el contacto entre el notario Luis Barbarán y algún maestro de esgrima, no podremos dar un indicio de quién, de entre los diferentes maestros del entorno, pudo con más probabilidad mandar redactar el texto.

60 Documento 7, AHPZ, sig. 79, fol. 81, (Bartolomé Anchías, 17 de julio de 1526).

61 Guilmaín Alonso, 2014: 2452. 


\section{APÉNDICE DOCUMENTAL}

\section{DOCUMENTO 1}

Las nueve reglas de la espada de dos manos

En nombre de Dios y del señor San / Gorge la primera regla del espada de / dos manos es /

Al mutante entrando la pierna drecha / fas mutante entrando la pierna yzquierda / quantas vezes quiseredes y lenta delante / y tornar entatras /

La segunda es mandrete entrando la pier / na drecha rebés entrando con la pierna / yzquierda quantas vezes quiseredes anzia / delante y anzia atrás. /

La tercer estocada dentrando la pierna / drecha y estocada dentrando la pierna / yzquierda quantas vezes quiseredes /

La quarta es mutante a pie quedo y entran / do con hun mandrete fas mutante a pie / quedo entrando con hun rebés quantas / vezes quisieres anzia delante y anzia trás /

La quinta estocada a pie quedo entrando (roto) / hun mandrete y estocada a pie quedo en (roto) / trando con hun rebés quantas vezes qui (roto: ¿sieres?) /

La sexta mutante a pie quedo rebés a pie (roto: ¿que?) / do estocada a pie quedo dentrando con hun (roto) / mandrete fas mutante a pie quedo mandr (roto: ¿ete?) / a pie quedo estocada a pie quedo dentrando (roto) / con hun rebés quantas bezes quisieres (roto) //

La séptima mutante con represa y otro mutan / te con represa dentrando con hun mandrete fas mu / tante con represa y otro fas mutante con represa den / trando con hun rebés quantas vezes quisieres. /

La octaua mutante con represa y otro mutante con re / presa rebés a pie quedo estocada a pie quedo den / trando con hun mandrete fas mutante con repre / sa fas mutante otro con represa mandrete a pie que / do estocada a pie quedo dentrando con hun rebés / quantas bezes. /

La nobena las reberencias es hun mutante al hun / costado otro al otro costado y otro mutante dentrando / la pierna yzquierda rebés a pie quedo estocada a / pie quedo dentrando con hun mandrete hazien / do reberencia mutante al hun costado otro al otro cos tado dentrando la pierna drecha con hun fas mutan / te adelante mandrete a pie quedo estocada a / pie quedo dentrando con hun rebés saliendoser con /

al mutante al hun costado y fas mutante al otro / (manchado: ¿y questo se a?) ga quantas vezes quisieres $/ 62$ (Bastardelo)

62 Final de las reglas, y comienzo de una sección de bastardelo que coincide con el protocolo descrito en la nota 18. 


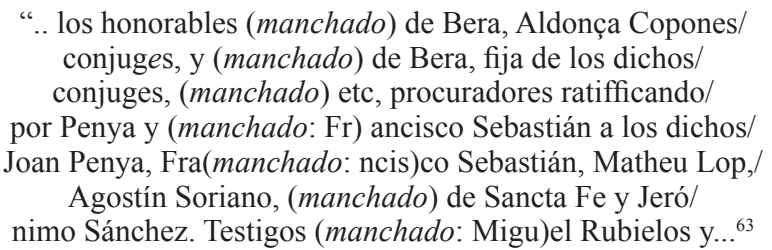

\section{DOCUMENTO 2}

Nombramiento del maestro mayor Alfonso de Robres por Juan II de Aragón. (Publicado por Manuel Serrano y Sanz en el Boletín de la Real Academia Española)

Nos don Iohan, por la gracia de Dios rey de Aragón... atendida la suficiencia, ydoneydat, fidelidat, e prohonbría de vos, el amado barbero nuestro Alfonso de Robres, maestro en la art de palestrina, dicho vulgarment de espada e broquer, por el dicho esguart, e ahun a humil soplicación de algunos domésticos e familiares nuestros, con e por tenor de la present scientment et expressa, damos e atorgamos lizencia, facultat e poder a vos dicho maestre Alfonso de Robles, que en los nuestros regnos de Aragón e de Valencia e principado de Catalunya, vos e no otro alguno siades examinador mayor de la dita arte de palestrina, siquiere del juego de spada e broquer... e queremos que vos dicho maestre Alfonso, e no otro... no pueda examinar de la dita arte, ni ser osado de levantar ni esleyr pebostre, ni bachiller, ni maestro, sino vos... Item, que ninguno no sía osado de poner plaça del dito juego sino vos, dito maestre Alfonso... Item, si vos dito maestre Alfonso enviaredes a llamar los dichos pabostres e bachilleres e maestros de la esgrima, e no quisiereren venir a vuestro llamamiento, que encorran en pena de diez florines... Item, que si vos dicho maestre Alfonso fallaredes alguno o algunos seyer examinados para qualquiere grado de los susodichos, antes del presente nuestro poder, e faladeres aquel o aquellos no seyer bien examinados que los podades coregir, emendar, encara fazerles mandamiento que no usen de la dicha arte, siquiere juego, encara que tuviessen carta de seyer maestros o de otro alguno de los grados susodichos, fins en tanto que aya tornado a deprender, e sía tornado al esamen vuestro o de vuestro substituydo... Item, si trobareys que alguno, encara maestre o graduado en alguno de los grados de suso dichos, o no aviendo aquellos, demostrara la dixa arte o juego d'espada a algun jodío, moro o esclavo, que encorra en pena de diez florines... Item, que podades dar licencia de parar plaça o plaças honestament a qualquiere maestro de la dita arte... Dada en Barcelona a veynte días de dezienbre en el anyo mil CCCCLVIII.

(A.P.Z. papeles sueltos) ${ }^{64}$

\section{DOCUMENTO 3}

Nombramiento del maestre mayor Pablo de Peralta por Fernando el Católico.

Pauli de Peralta.

Nos, don Ferrando, etc, por quanto hauemos entendido que vaca el officio de maestre mayor de esgrima de los nuestros reynos de Aragón, Valencia y Cathaluña y condados de Rossellón y Cerdanya, por muerte de Alonso de Robles, que lo tenía por concessión del serenissimo rey don Juan, padre y predecessor nuestro, de inmortal memoria, confiando mucho de la fe, habilitat, y sufficiencia de vos, fiel nuestro maestro Pablo de Peralta, a intercessión del illustre y muy reuerendo arçobispo de Çaragoça y de Monreal, nuestro muy caro e muy amado fijo y lugarteniente general, con tenor de las presentes, de nuestra cierta sciencia el dicho officio de, e en la manera susodicha, o en qualquiere otra manera vacante, a vos el dicho maestre Pablo de Peralta, toda vuestra vida durante, otorgamos y enconmendamos, en assí que vos dicho maestre Pablo de Peralta durante vuestra vida, como es dicho, seays maestro mayor de sgrima de todos los dichos tres reynos y condados, y tengays, rijays e posseays el dicho officio, fielmente, leal y bien hayays assimismo, y recibays, y a vuestros vsos y vtilidades appliqueys el salario añual y ganancias, derechos, obtienciones y emolumentos justos y acostumbrados, y al dicho officio deuidos y pertenescientes y aquellos que por el dicho Alonso de Robles y otros predecessores vuestros en el dicho officio hauer y recebir son acostumbrados, y por lo semejante gozeys y vseys de todos aquellos priuilegios, prerogatiuas, preheminencias, libertades, exempciones, inmunidades, franquezas y otras cosas al dicho officio deuidas y pertenecientes queremos, empero que antes que vos dicho maestro Pablo de Peralta (bibliófagos: ¿tomaredes?) possession del dicho officio seays tenido y obligado de jurar, en poder de aquellas personas tocare que bien y fielmente y leal vos haureys en el regimiento e exercicio del officio susodicho//, y fareys qualesquiere otras cosas, a las quales sereys tenido y obligado por lo qual a la serenissi-

63 Final del fragmento de bastardelo conservado.

64 No sabemos dónde se encuentra actualmente. Los "papeles sueltos" de comienzos de siglo fueron posteriormente indexados en diferentes notarios, sin que conste escritura de cuáles exactamente. 
ma dona Joana reyna de Castilla, de León, de Granada, etc, princesa de Gerona, archiduquesa de Austria, e duquessa de Borgoña, etc, nuestra muy cara e amada fija primogenita, e gouernatriz general, e despues de nuestros bienauenturados días, heredera y legittima successora, declarando nuestra intención so la bendición paternal dezimos al dicho illustre y muy reuerendo arçobispo de Çaragoça y de Monreal, nuestro muy caro e muy amado fijo y lugarteniente general, affectuosamente rogamos, y a los spectables nobles, magníficos amados conseieros y fieles nuestros, qualesquiere lugarestenientes generales y portant vezes de nuestro general gouernador en los dichos nuestros reynos de Aragón, Valencia y Cathaluña, y condados de Rossellón y Cerdanya, y en los dichos officios lugarestenientes, vegueres, justicias, bayles, sobrejunteros, çalmedinas, merinos, jurados, y otros qualesquiere officiales, y súbditos nuestros en los dichos reynos y condados constituydos y constituydores, y a los lugarestenientes presentes y venideros, dezimos y mandamos de la dicha nuestra cierta sciencia y expressamente so incorrimiento de la ira e indignación nuestras y pena de tres mil florines de oro de Aragón de los bienes de qualesquiere que el contrario fiziere, irremissiblemente, exigidores y a nuestros cofres applicadores, que a vos, dicho maestro Pablo de Peralta, toda vuestra vida durante, segund es dicho, por maestro mayor de sgrima en los reynos y condados ya dichos, tengan, reputen, honren y tracten, y a aquellos a quien perteneciere respondan y responder fagan de los dichos salario, derechos y otros emolumentos, y os dexen gozar (tachado: pagar) de los priuilegios, exempciones, inmunidades, franquesas, perrogatiuas y otras cosas susodichas, y esta nuestra carta o priuilegio, y todas las// otras cosas en él contenidas tengan firmamente, guarden y obseruen, tenir, guardar y obseruar fagan inuiolablemente por aquellas personas quien se esguardare, y no fagan ni permitan que sea fecho lo contrario por razón o causa alguna, si la dicha sereníssima reyna princessa, y nuestra muy cara fija, nos dessea obedecer, y los otros officiales y súbditos nuestros susodichos nuestra gracia tienen cara, e la ira e indignación nuestras y pena susodicha encorrer no dessean, en testimonio de lo qual mandamos ser fechas las presentes con nuestro sello común en pendiente selladas. Datum en la ciudat de Seuilla, a V días del mes de nouiembre, en el año del nascimiento de nuestro Señor mil quinientos y ocho, y de los reynos nuestros, assaber es de Sicilia allende el Far, ${ }^{65}$ año quarenta y vno de Aragón, y de los otros trenta de Sicilia aquende el Far, y de Hierusalem seys.

Yo el rey.

Dominus rex mandavit, michi Michaeli Velasquez Climent. Visa per thesaurarium et conservatores generales.

\section{DOCUMENTO 4}

Licencia otorgada por el maestro Pablo de Peralta (Al margen: Liçencia)

Die septima mensis aprillis anno quo supra quingentesimo decimo sexto, Cesarauguste.

Eadem die, yo, Pablo de Peralta, maestro de sgrima (supralineal: en los regnos de Aragón, Cathalunya y Balencia e condado de Rosellón y Cerdanya), hauitant en la ciudat de Çaragoça, con priuilegio a mí atorgado por el rey nuestro señor, don Ferrando de Aragón, de inmortal memoria, que dado fue en la ciudat de Seuilla a cinco días del mes de nouiembre del anyo mil quinientos y ocho, firmado de mano de su real magestat y expedido por el magnífico Miguel Velázquez Climent, prothonotario del dicho señor rey, con todas las otras solenidades. Por tanto de grado, etc, por el poder e facultat a mi dado en el dicho priuilegio, doy permiso, licencia y facultat a vos, Joan de Montesa, criado del expectable señor don Luys, señor de Yxar y conde de Velgit, ${ }^{66}$ hauitant en la dicha villa de Yxar, que podays como licenciado durant mi beneplácito y no más (tachado: parar), demostrar de sgrima en los dichos regnos y condados (tachado: exceptado en la), y por joyas, exceptado en las ciudades de Çaragoça, Varcelona y Balencia, y a otros que se dixeren maestros requerir (supralineal: vos) demuestren sus priuilegios, y si no vos los mostraran, requerir se salgan de la ciudat, villa o lugar donde estareys, dentro les dichos regnos y condados (supralineal: e para demandar, exhigir e cobrar aquellos salarios e emolumentes que hun maestro de sgrima puede demandar exhigir y cobrar, etc.). E a los criados que tenrreys y otros que querran esgrimir (tachado: y a los), y assí a las joyas, como en otra qualquiere manera, quitar de enojo y questiones poner paz y amor entre ellos, etc. E el dicho Joan de Montesa juró de bien y lealmente hacerse, por Dios, etc. Velgit.

Testes Dionis de Ubún, infançón, e mossén Alonso Serón, cauallero alcayde de Vinaceit, criados del conde de

\footnotetext{
65 Parece referirse al Estrecho de Mesina, o Boca de Far.

66 Sic (Belchite).
} 


\section{DOCUMENTO 5}

Examen para Francisco Cristóbal, de los grados de jugador y preboste, por el maestre mayor Pablo de Peralta, en un corral de Zaragoza.

(Al margen: Instrumentum gradus de pabostre et jugador in arte gladiatoria)

In die nomine amen nouerint vniversi, quod anno a natiuitate domini millesimo quingentesimo vicesimo sexto die videlizet intitulato secundo mensis january apud quasdam domos sitas in parrochia Sancti Philippi presentis ciuitatis Cesarauguste, et dentro hun corral de aquellas//, delante el honrrado Pablo de Peralta, habitante en la dicha ciudat de Çaragoça, maestro mayor del arte de la sgrima y examinador mayor de aquella, elegido y creado por la sacra maiestat del rey y señor nuestro don Ferrando por la gracia de Dios, rey de Aragón, etc, de gloriosa memoria mediante hun priuilegio real en pargamino scripto de la mano del dicho señor rey nuestro señor firmado y con el sello real común, en pendiente sellado, que fue dado el dicho real priuilegio en la dicha ciudad de Çaragoça a trenta días del mes de nouiembre en el anyo del nascimiento de nuestro Señor mil quinientos y dizio//cho, ${ }^{67}$ despachado en la forma que semejantes priuilegios suelen y se acostumbran en dicha corte despachar, el qual dicho priuilegio después por la magestad del emperador y rey nuestro señor don Carlos fue confirmado.

Presentes los honorables mastre Luis de Folguera, mastre Sabastián de Soria, et mastre Pedro Román, maestros de la mesma arte de la sgrima, vezinos de la mesma ciudat de Çaragoça, et otras mutchas personas allí presentes, compareció et fue personalmente constituydo el honorable Gabriel Golí (supralineal: ymaginero), pabostre en la mesma arte de la sgrima y habitante en la mesma ciudat de Çaragoça el qual presienta a los dichos maestros y delante aquellos, etc, a Francisco Cristóual scudero, habitante Cesarauguste, haijado suyo, el qual dicho Gabriel Golí, assí como padrino del dicho Francisco Cristóual, haijado suyo por el presentado, dreçando sus palabras al dicho mastre Pablo de Peralta, maestro mayor// sobredicho, dixo y propuso en effecto las siguientes.

Que como el dicho su haijado, por luengo tiempo, en la disciplina del arte de la dicha sgrima se haya excercitado, y haya fecho muchos y diuersos actos en el exercicio es assaber de spada de dos manos et de spada y broquelejo pequenyos, et como el dicho su haijado desseasse a los grados de jugador y de pabostre en lo sobredicho por el exercitado, conuolar, etc, que por tanto rogaua et requería en el mesmo nombre, como de fecho rogó y requirió al dicho maestre Pablo de Peralta, maestro mayor, etc, sobredicho, que por que mejor, etc, el dicho Francisco Crstóual, haijado suyo, los dichos grados de jugador y pabostre en la(sic) sobredichas cosas, en las quales como dicho es, se ha exercitado, alcançar pudiesse, etc, al mesmo su haijado diligentemente examinasse de su pericia y sufficiencia en la arte sobredicha, en lo sobredicho por el dicho su haijado exercitado, como el dicho su haijado fuesse presto y aparejado, Deo sibi propicio, de lo mesmo en la dicha arte de la sgrima por el exercitado// iuxta sus fuerças responder, etc. Et el dicho maestre Pablo de Peralta, maestro mayor sobredicho, viendo el desseo del dicho haijado del dicho Gabriel Golí ser justo, rogó al dicho maestre Sabastián de Soria que examinasse al dicho Francisco Cristóual en lo sobredicho por el exercitado, como dicho es, del arte de la sgrima por que mejor se le pudiessen dar los sobredichos grados, etc, et en continente en presencia de mí, Joan de Gurrea, notario, y de los testigos inffrascriptos, y de los arriba nombrados maestros, y de otras personas qui allí presentes estauan y lo veían, el dicho maestre Sabastián de Soria, a rogarías del sobredicho maestre Pablo de Peralta, etc, procilió(sic) al examen de los sobredichos grados de jugador y pabostre (tachado: en lo sob) del mesmo Francisco Cristóual, haijado susodicho, en lo sobredicho por el mesmo Francisco Cristóual, etc, exercitado del arte de la sgrima como arriba se ha dicho.

Desta forma que tomadas por ellos mesmos sendas spadas de dos manos procilieron a diuersos actos del exercicio del arte sobredicha, y dexadas las sobredichas spadas de dos manos//, y tomadas por ellos sendas spadas pequenyas con sus broquellejos, procilieron a diuersos actos de este mesmo exercicio de la sobredicha arte de la sgrima. Et el dicho Francisco Cristóual, haijado sobredicho del dicho Gabriel Golí, a lo interrogado por el dicho maestre Sabastián de Soria, assí se hubo y respondió que assí el dicho maestre Sabastián de Soria, como los sobredichos maestre Pablo de Peralta, maestro mayor, maestre Luis de Folguera et maestre Pedro Román fueron y quedaron muy contentos.

Assí que prestito prius, solemne juramento por el dicho Francisco Cristóual, etc, en poder y manos del sobredicho Gabriel Golí, etc, padrino suyo por Dios, etc, de tener, etc, todas aquellas solemnidades del arte sobredicha, las quales al dicho haijado el mesmo su padrino de palabra le explicó, y senyaladamente, que a todo su poder con las spada desuaynada en la mano deffendera la sancta fe cathólica, assi mesmo que por deffensión de las viudas, pupillos y huérfanos no reusara de tomar tra//bajo[....] (Juramentos, concesión, consignación de testigos y nota de expedición de documento similar para Francisco de Cambra)

67 Peralta está confundiendo la fecha del nombramiento hecho por Fernando con la de la confirmación hecha por Carlos.

Gladius, XXXVII (2017), pp. 153-170. ISSN: 0436-029X. doi: 10.3989/gladius.2017.06 


\section{DOCUMENTO 6}

Obligación entre el maestro Pablo de Peralta y Francisco de Cambra para enseñar y otorgar el título de maestro de esgrima.

(Al margen: Obligación)

Yo, maestre Pablo de Peralta, maestro mayor del arte de la sgrima en los reynos de Aragón, etc, habitante en la ciudat de Çaragoça, attendiente y considerante que vos el honorable Francisco Cristoual, pabostre ya del arte sobredicha de la sgrima, y habitante en la mesma ciudat, teneys mucha voluntat y desseays llegar a ser maestro en dicha arte de la sgrima, et para alcançar el sobredicho magisterio, me havéis rogado os ensenyase lo que hauéys menester para el examen del dicho magisterio y oss diesse y creasse en maestro de dicha arte de la sgrima. Por tanto de grado, etc, a rogarías, etc, prometo, etc//, de demostrar, y que demostraré y ensenyaré a vos dicho Francisco Cristóual lo necessario para dicho (supralineal: vuestro) examen, etc. Con esto empero que vos pongays toda la diligencia que podays en tomar lo que yo os enssenyare. Et assí mesmo de dar, y que os daré, etc, el dicho grado de maestro, fasta el día y fiesta de la Pascua de mayo primera veniente del año presente, etc, inclusiue et si ante puedo ante. Con esto empero que vos pongays la dicha diligencia de deprender lo que yo os ensenyare para dicho examen. Et prometto, etc, fazer, etc, lo sobredicho con que vos, dicho Francisco Cristóual, me hayays dar realmente et de fecho, por yo hazer lo que de parte de arriba prometto, es assaber diez florines de buen oro, en oro, etc, en esta manera. Los tres florines por el día de Pascua de Resurrectión primero veniente del mesmo año presente, et los restantes siete florines el día del di//cho examen y magisterio et toda hora que yo os haure dado el dicho grado de maestro. Et encara con esto que vos dicho Francisco Cristoual hayas de pagar y pagueys el drecho de los otros maestros que interuendrán en dicho vuestro magisterio, et deys la comida que se acostumbra dar, etc, large.

Et yo dicho Francisco Cristóual, qui a lo sobredicho presente soy, de grado, etc, prometto, etc, de primar de tomar y poner diligencia en deprender lo que por vos dicho señor maestre Pablo de Peralta, etc, para dicho mi examen de maestro me fuere ensenyado, et prometto encara et me obligo de pagar y que pagaré a vos, dicho señor maestro Pablo de Peralta, los dichos diez florines de oro en oro, en contantes en la forma y manera por vos arriba recitada, siempre que por vos me fuere dado el dicho grado de maestro da la dicha arte de la sgrima en el tiempo por vos, dicho maestre Pablo de Peralta, arriba puesto//, et de pagar y que pagaré el drecho de los otros maestros de la mesma arte que interuendran en dicho mi examen y magisterio, et de dar y que daré la comida acostumbrada dar en semejantes magisterios. Et assí nos, dichos maestre Pablo de Peralta ex vna, et Francisco Cristóual ex altera, firmamos, etc, large [...] (Lenguaje jurídico y consignación de testigos)

\section{DOCUMENTO 7}

Alquiler de un corral por el maestro Pedro Marco Oliver para demostrar esgrima. (Al margen: Locación)

Die XVII july anno quo supra, Cesarauguste

Eadem die, etc, yo, Joan de Molina, notario, causídico y habitante en la dicha ciudat de Çaragoça, certifficado, etc, de mi cierta sciencia, do a loguero, si quiere luego, a vos el honorable maestre Pedro Oliuer, maestro de sgrima, habitante Cesarauguste, assaber es vn corral mío para vuestro exercicio de mostrar de sgrima, el qual corral es situado en la dicha ciudat, y assí con (tachado: casas) corral de don Ynygo de Mendoça, y con casas de mí, dicho Joan de Molina, y con la calle llamada El Cosso, por tiempo de vn año contadero de hoy en delante, por precio en el dicho año de setenta sueldos jaqueses pagaderos en dos tandas yguales, assaber es a Sanct Joan y a Todos Sanctos y con las condiciones siguientes. Et primo que vos, dicho maestre Oliuer, durante el dicho tiempo hayays de venir a demostrar a vuestros criados en los días fazenderos a las tres horas después de mediodía, y en los días de fiesta a la vna hora después de mediodía, y con las dichas condiciones, etc, vos luego, siquiere alquilo el dicho corral, etc, y prometo durante el dicho tiempo de tenerhos en pacíffica possessión de aquel, etc. Et yo dicho maestre Pedro (supralineal: Oliuer), qui presente stoy, etc accepto la dicha locación, por el dicho tiempo y precio y condiciones, y prometo pagar y seruar aquellas//, large, etc, a lo qual la vna parte a la otra respectiue obligamos, etc, renunciamos, etc, large.

Testes Diego Romero, trompeta del illustre señor arçobispo de Çaragoça, y Francisco Vrgel, trompeta del illustre señor mossén Joan de Lanuça, visorey de Aragón, habitantes Cesaraguste. 


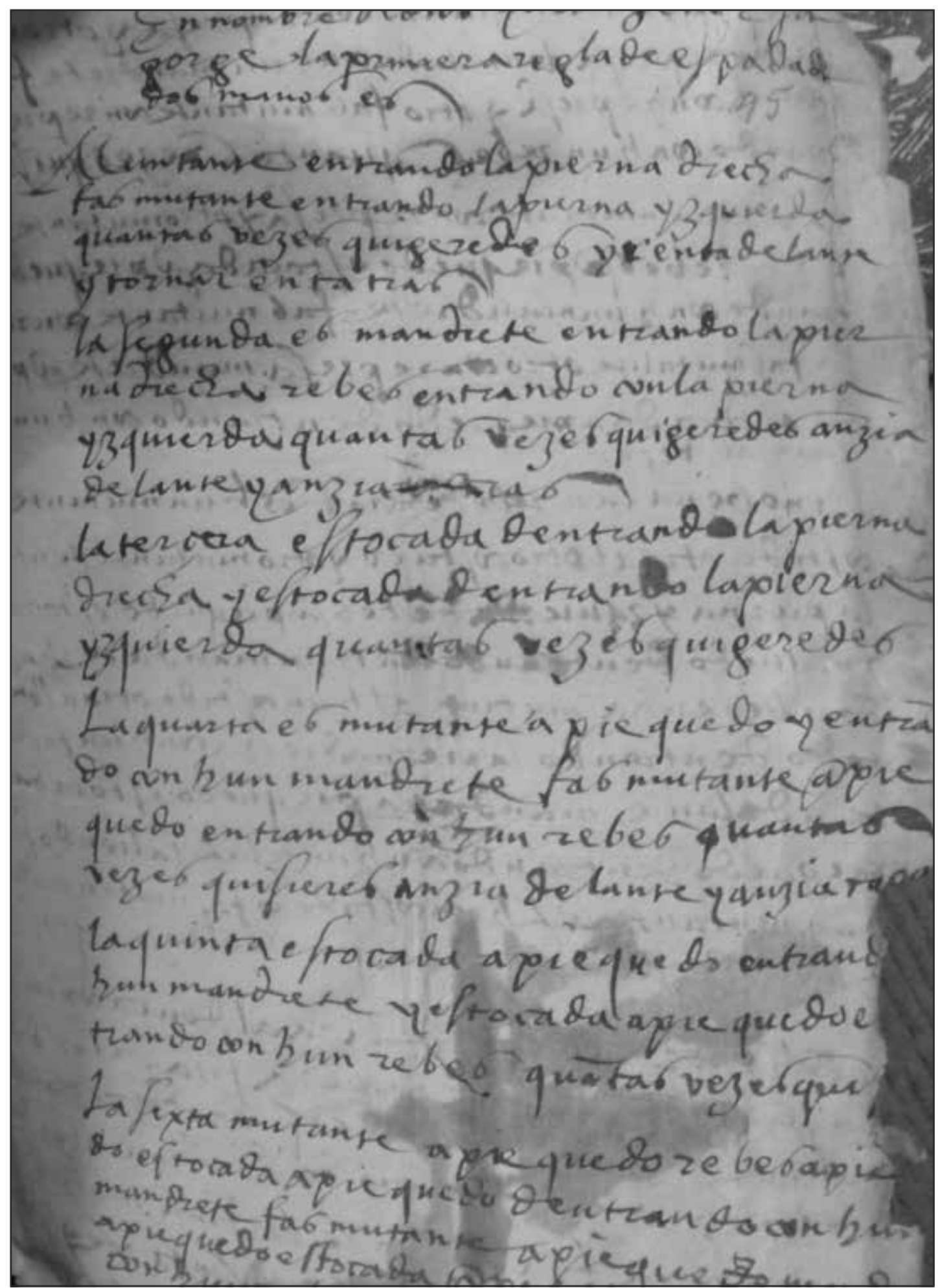

Figura 1. Las nueve reglas de la espada de dos manos. 


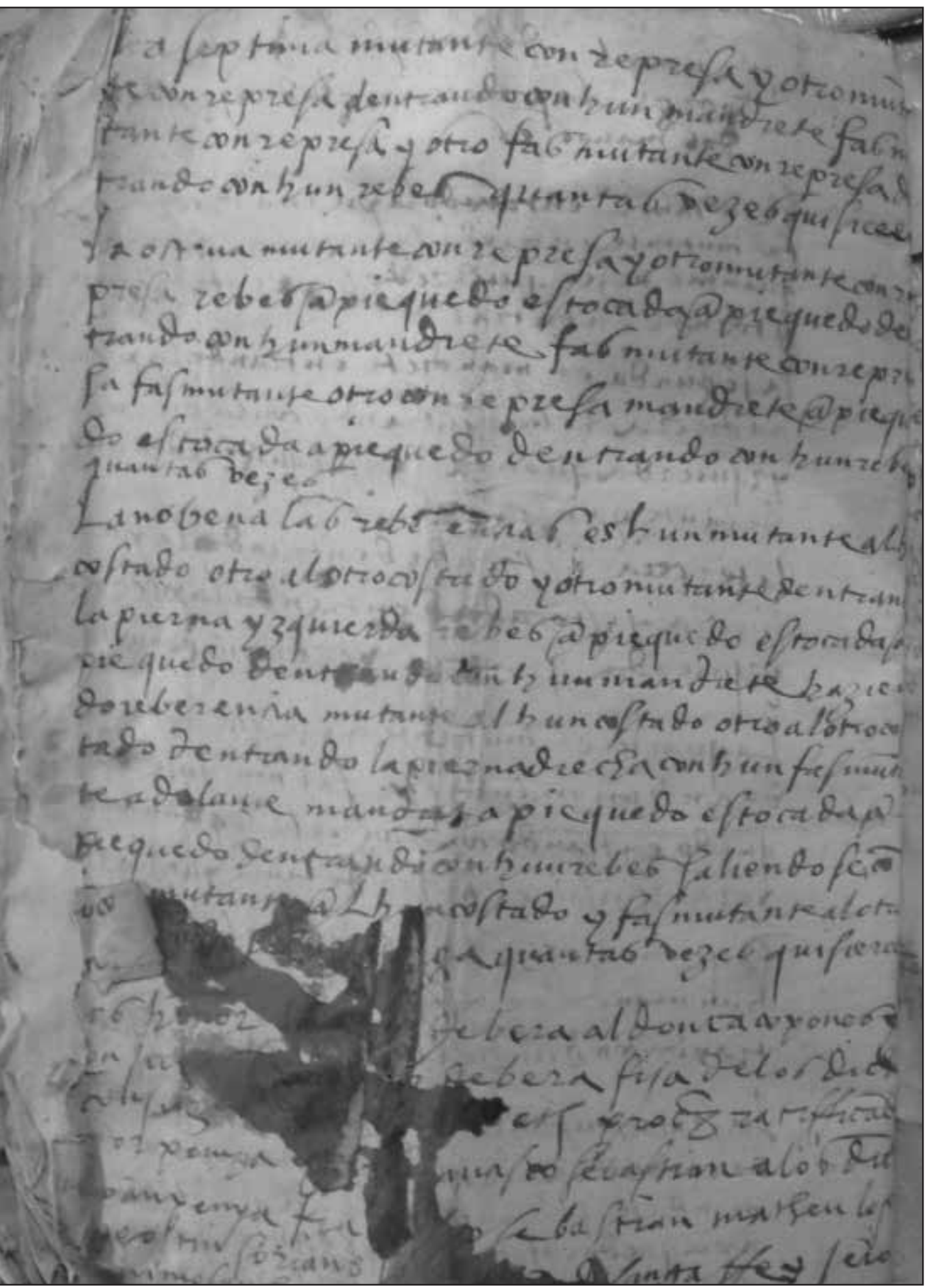

Figura 2. Las nueve reglas de la espada de dos manos, reverso. 


\section{BIBLIOGRAFÍA}

Abizanda y Broto, M. (1917): Documentos para la historia artística y literaria de Aragón, procedentes del Archivo de Protocolos de Zaragoza. Siglo XVI, tomo II. Zaragoza, Tip. "La Editorial”.

Anglo, S. (2000): The Martial Arts of Renaissance Europe. New Haven \& London, Yale University Press.

Cabezudo Astrain, J. (1962): «Un bilbaíno se examina de esgrima en 1503, en Barbastro». Boletín de la Real Sociedad Vascongada de los Amigos del País, año 18, cuaderno 1: 83-86.

Ceballos-Escalera y Gila, A. (1997): «El Maestro Mayor de la Destreza de las Armas (un oficio bajomedieval en los orígenes de la esgrima española)». Colaboraciones, 6: 77-108.

Gracia Lasheras, J. C. (2014): «El memorial de actos del notario Joan Abat de zaragoza entre 1493 y 1510». Aragón en la Edad Media, 25: 61-100.

Guilmaín Alonso, J. (2014): «Francisco Román, maestro de las armas del Emperador, y su perdido Arte de la Esgrima», Reunión Científica de la Fundación Española de Historia Moderna, 4-6 de Junio de 2014. Universidad de Sevilla: 2151-2167.

Leguina y Vidal, E. (1904): Bibliografia e Historia de la Esgrima Española. Madrid, Fortanet.

Leva Cuevas, J. (2004): «La Caballería y el Arte de la Esgrima en la ciudad de Córdoba en los siglos XV y XVI. La plaza de la Corredera como marco de su ejercicio». Ámbitos. Revista de estudios de Ciencias Sociales y Humanidades, 11: 107-124.

Llompart Moragues, G. (1976-1977): «Ideal caballeresco y escuela de esgrima en Mallorca en el siglo XV». Cuadernos de historia Jerónimo Zurita, 29-30: 149-162.

Nievas Muñoz, D. (2012): La esgrima y el mundo de la espada en la España Moderna. Máster universitario oficial "La Monarquía Católica. El Siglo de Oro español y la Europa barroca”, tutor: Antonio Jiménez Estrella. Granada, Universidad de Granada.

Serrano y Sanz, M. (1916): «Palestrina=Esgrima». Boletín de la Real Academia Española, III: 240.

Valle Ortiz, M. (2012): Nueva Biografia de la Antigua Esgrima y Destreza de las Armas. Santiago de Compostela, AGEA, Edizer.

Valle Ortiz, M. y Dill Curtis, M. (2009): «Un texto de esgrima española del siglo XVI», Materiales para la historia del deporte, $7: 35-42$.

Recibido: 28-05-2016

Aceptado: 14-12-2016 